\title{
Penanaman Nilai Karakter dan Moral Mahasiswa Melalui Mata Kuliah Anak Berkebutuhan Khusus dan Pendidikan Inklusi
}

\author{
Bayu Pamungkas \\ Universitas PGRI Yogyakarta, Indonesia \\ bayu.pamungkas@upy.ac.id
}

\section{Informasiartikel}

Kata kunci:

Nilai Karakter dan

Moral,

Anak Berkebutuhan

Khusus,

Pendidikan Inklusi

\section{Keywords:}

Character and Moral

Values,

Children with Special

Needs,

Inclusive Education

\begin{abstract}
ABSTRAK
Penelitian ini bertujuan untuk mengetahui penanaman nilai karakter dan moral mahasiswa melalui mata kuliah Anak Berkebutuhan Khusus dan Pendidikan Inklusi mahasiswa prodi PGSD FKIP UPY. Desain penelitian menggunakan pendekatan kualitatif dan metode yang digunakan adalah studi kasus. Partisipan dalam penelitian ini adalah mahasiswa semester tujuh pada mata kuliah Anak Berkebutuhan Khusus dan Pendidikan Inklusi prodi PGSD FKIP UPY. Teknik pengumpulan data menggunakan observasi, wawancara, dokumentasi. Pengujian keabsahan data dengan cara perpanjangan pengamatan dan triangulasi. Teknik pengolahan dan analisis data menggunakan analisis proses siklus yang interaktif yang terdiri dari reduksi data, penyajian data, dan verifikasi data. Hasil penelitian adalah terdapat beberapa nilai karakter dan moral yang dapat ditanamkan pada mata kuliah Anak Berkebutuhan Khusus dan Pendidikan Inklusi antara lain: toleransi, semangat kebangsaan, bersahabat/komunikatif, peduli sosial dan tanggung jawab.
\end{abstract}

\begin{abstract}
Planting Student Values and Morals Through Courses in Children with Special Needs and Inclusive Education. This study aims to discover the establishing of PGSD FKIP UPY students' character value and moral through learning subjects; special needs children and inclusive education. This study uses qualitative design and the method of the study is case study. Participants of this study are the $7^{\text {th }}$ semester students of special needs children and inclusive education classes in PGSD FKIP UPY. The data collection procedures used observation, interview, and documentation as the instruments. It applied triangulation data and in-depth observation in the validation test. The data were analyzed by looking at interactive cycle analysis process which consisting of data reduction, data presentation, and data verification. The result shows that there are some characters and moral values that can be established during special need children class and inclusive education class. They are tolerance, national spirit, sociable and responsive, care, and responsible.
\end{abstract}

Copyright @ 2018 Bayu Pamungkas. All Right Reserved

How to Cite: Pamungkas, B. (2018). Penanaman Nilai Karakter dan Moral Mahasiswa Melalui Mata Kuliah Anak Berkebutuhan Khusus dan Pendidikan Inklusi. Jurnal Moral Kemasyarakatan, 3(1), 23-28. . 


\section{Pendahuluan}

Undang-Undang Sistem Pendidikan Nasional No. 20 tahun 2003 Pasal 3 menjelaskan bahwa "Pendidikan nasional berfungsi mengembangkan dan membentuk watak serta peradaban bangsa yang bermartabat dalam rangka mencerdaskan kehidupan bangsa, bertujuan untuk berkembangnya potensi peserta didik agar menjadi manusia yang beriman dan bertakwa kepada Tuhan Yang Maha Esa, berakhlak mulia, sehat, berilmu, cakap, kreatif, mandiri, dan menjadi warga negara yang demokratis serta bertanggung jawab" (UU Sisdiknas, 2003). Tujuan pendidikan nasional tersebut merupakan rumusan mengenai kualitas manusia Indonesia yang harus dikembangkan oleh setiap satuan pendidikan.

Salah satu wujud implementasi dari Undang-Undang Sistem Pendidikan Nasional No. 20 tahun 2003 di perguruan tinggi adalah dicanangkanya Mata Kuliah Anak Berkebutuhan Khusus dan Pendidikan Inklusi pada Prodi Pendidikan Guru Sekolah Dasar (PGSD) Fakultas Keguruan dan Ilmu Pendidikan (FKIP). Mata Kuliah Anak Berkebutuhan Khusus dimaksudkan untuk membekali mahasiswa agar memiliki pengetahuan, pemahaman, dan keterampilan dalam mendampingi anak berkebutuhan khusus. Mata kuliah ini difokuskan pada materi yang berkaitan dengan anak berkebutuhan khusus, yaitu anakanak dengan kekhususan sebagai berikut: (1) tunanetra, (2) tunarungu, (3) tunagrahita, (4) tunadaksa, (5) tunalaras, (6) autis, (7) tunaganda, (8) anak berkesulitan belajar, (9) anak cerdas istimewa bakat istimewa. Sedangkan mata kuliah Pendidikan Inklusi bertujuan untuk membekali mahasiswa agar memiliki pengetahuan tentang pendidikan SD Inklusif dan mampu membantu menangani siswa berkebutuhan khusus di SD Inklusif. Mata Kuliah ini meliputi konsep SD Inklusif, identifikasi dan asesmen siswa berkebutuhan khusus, dan penanganan siswa berkebutuhan khusus.

Fakta di lapangan menunjukkan bahwa materi mata kuliah Anak Berkebutuhan Khusus dan Pendidikan Inklusi sebagai salah satu mata kuliah wajib pada Program Studi Pendidikan Guru Sekolah Dasar akan menjadi sangat teoritis bagi mahasiswa ketika mahasiswa hanya belajar konsep tentang Anak Berkebutuhan Khusus dan Pendidikan Inklusi tanpa disertai upaya nyata menerapkan materi tersebut dalam lingkungan sosial. Lebih lanjut tanpa adanya implikasi materi kedua mata kuliah tersebut, penanaman nilai karakter dan moral mahasiswa untuk peduli membantu layanan dan bimbingan bagi anak berkebutuhan khusus tidak dapat berjalan optimal.

Esensi Mata Kuliah Anak Berkebutuhan Khusus dan Pendidikan Inklusi sangat erat kaitanya dengan nilai karakter dan moral. Dalam pendidikan karakter di Indonesia, tercakup 18 pilar / nilai karakter yang perlu dikembangkan dalam penyelenggaraan pendidikan, yakni :

Tabel 1. 18 Nilai Karakter

\begin{tabular}{|l|l|}
\hline Religius & Semangat Kebangsaan \\
\hline Jujur & Cinta Tanah Air \\
\hline Toleransi & Menghargai Prestasi \\
\hline Disiplin & Bersahabat / Komunikatif \\
\hline Kerja Keras & Cinta Damai \\
\hline Kreatif & Gemar Membaca \\
\hline Mandiri & Peduli Lingkungan \\
\hline Demokratis & Peduli Sosial \\
\hline Rasa Ingin Tau *Pusat Kurikulum Balitbang Diknas (2011)
\end{tabular}

Terkait dasar, fungsi dan pilar pendidikan karakter pada beberapa paparan tersebut, pendidikan karakter tidak dapat dipisahkan dengan pendidikan inklusi yang sarat dengan keberagaman. Beberapa pilar (toleransi, semangat kebangsaan, bersahabat / komunikatif, peduli sosial dan tanggung jawab) merupakan modal dalam penyelenggaraan pendidikan di sekolah inklusif (Pamungkas, 2016: 457). Berdasarkan hal tersebut fokus penelitian ini adalah pendeskripsian secara mendalam pelaksanaan perkuliahan Mata Kuliah Anak Berkebutuhan Khusus dan Pendidikan Inklusi untuk menanamkan nilai karakter dan moral mahasiswa. 


\section{Metode}

Desain penelitian yang digunakan dalam penelitian ini adalah pendekatan kualitatif. Peneliti menggunakan pendekatan kualitatif karena penelitian ini merupakan penelitian lapangan untuk mendeskripsikan dan menganalisis fenomena, peristiwa, aktifitas suatu kelompok dalam hal ini adalah pelaksanaan perkuliahan Mata Kuliah Anak Berkebutuhan Khusus dan Pendidikan Inklusi di Prodi PGSD FKIP Universitas PGRI Yogyakarta. Sejalan dengan tujuan dan rumusan masalah penelitian, penelitian ini menggunakan pendekatan kualitatif dengan menggunakan metode penelitian kualitatif deskriptif dengan desain studi kasus. Langkah-langkah yang dilakukan dalam analisis data yaitu melalui reduksi data, penyajian data atau display data dan penarikan kesimpulan (konklusi) dan verifikasi dengan partisipan penelitian adalah mahasiswa PGSD UPY Semester 7 yang terdaftar pada mata kuliah Anak Berkebutuhan Khusus dan Pendidikan Inklusi.

\section{Hasil dan pembahasan}

Mata kuliah Anak Berkebutuhan Khusus dan Pendidikan Inklusi merupakan mata kuliah wajib dengan bobot masing-masing 2 SKS yang harus ditempuh oleh mahasiswa prodi PGSD. Materi yang dibahas dalam mata kuliah Anak Berkebutuhan Khusus adalah materi yang berhubungan dengan bergabagai jenis kemampuan, hambatan, dan kebutuhan khusus anak-anak yang berbeda dengan anak pada umumnya. Sedangkan mata kuliah Inklusi lebih menekankan materi pada bagaimana membantu anak berkebutuhan khusus untuk dapat memperoleh layanan pendidikan bersama anak lain yang tidak berkebutuhan khusus.

Selain membekali mahasiswa dalam mengenal ragam kebutuhan khusus anak, dua mata kuliah tersebut (Anak Berkebutuhan Khusus dan Pendidikan Inklusi) juga bertujuan agar mahasiswa memiliki karakter terutama kepedulian dengan anak berkebutuhan khusus di lingkungan sekitarnya. Dalam mencapai tujuan tersebut, perkuliahan Mata Kuliah Anak Berkebutuhan Khusus dan Pendidikan Inklusi dilaksanakan dalam 3 setting perkuliahan. Ketiga setting perkuliahan tersebut dipaparkan dalam tabel 2 berikut:

Tabel 2. Setting Perkuliahan Mata Kuliah ABK dan Pendidikan Inklusi

\begin{tabular}{|c|c|}
\hline Setting Perkuliahan & Kegiatan Perkuliahan \\
\hline Setting Pertama & $\begin{array}{l}\text { Dalam setting ini, selama setengah semester } \\
\text { mahasiswa memperoleh bekal dasar tentang } \\
\text { konsep umum anak berkebutuhan khusus dan } \\
\text { pendidikan inklusi. Setting ini dilakukan dengan } \\
\text { penjelasan dari peneliti selaku dosen dua mata } \\
\text { kuliah tersebut, presentasi kelompok dan tes } \\
\text { tertulis terkait materi yang telah dipelajari. }\end{array}$ \\
\hline Setting Kedua & $\begin{array}{l}\text { Dalam setting ini, selama setengah semester } \\
\text { berikutnya mahasiswa melakukan observasi } \\
\text { lapangan terbimbing serta wawancara di Sekolah } \\
\text { Luar Biasa (SLB), Sekolah Dasar (SD) yang } \\
\text { menerapkan program inklusi maupun lingkungan } \\
\text { masyarakat yang di dalamnya terdapat anak } \\
\text { berkebutuhan khusus. Perkuliahan dilakukan } \\
\text { secara kontekstual (praktek langsung) tetapi } \\
\text { dengan tetap dalam pembimbingan dosen } \\
\text { pengampu mata kuliah dalam hal ini peneliti } \\
\text { sendiri. }\end{array}$ \\
\hline Setting Ketiga & $\begin{array}{l}\text { Setting ini dilakukan dengan penyususnan } \\
\text { laporan hasil observasi lapangan dan wawancara } \\
\text { yang dilakukan oleh mahasiswa serta penyusunan } \\
\text { program pembelajaran. }\end{array}$ \\
\hline
\end{tabular}


Hasil observasi dalam penelitian ini menunjukkan bahwa setting pertama ditekankan pada memberikan pengetahuan pada mahasiswa terkait anak berkebutuhan khusus dan inklusifitas untuk membangun pengetahuan moral mahasiswa utamanya kepedulian terhadap anak berkebutuhan khusus di lingkunganya. Setting kedua dalam perkuliahan lebih ditekankan agar mahasiswa memiliki perasaan moral dengan melihat langsung keadaan dan proses pendidikan anak berkebutuhan khusus. Sedangkan setting terakhir menekankan pada kemampuan mahasiswa bertindak berdasarkan pengetahuan dan pengalaman langsung yang telah diperoleh pada setting perkuliahan pertama dan kedua.

Hasil wawancara menunjukkan bahwa dengan praktek langsung (pembelajaran dan pengajaran kontekstual) mengunjungi anak berkebutuhan khusus baik yang bersekolah di SLB maupun SD Inklusif, mahasiswa dapat lebih memahami esensi materi perkuliahan dan menerapkan langsung materi yang mereka pelajari. Dengan kefahaman dan pengalaman tersebut mereka merasa memilki tingkat kepedulian yang lebih kepada anak berkebutuhan khusus, toleransi dengan berbagai keberagaman siswa, dan dapat menjalin komunikasi yang lebih intens dengan anak berkebutuhan khusus.

Pembelajaran dan pengajaran kontekstual melibatkan peserta didik dalam aktivitas penting yang membantu mereka mengaitkan pelajaran akademis dengan konteks kehidupan nyata yang mereka hadapi. Dengan mengaitkan keduanya, peserta didik melihat makna di dalam tugas. Ketika peserta didik menyusun proyek atau menemukan permasalahan yang menarik, ketika mereka membuat pilihan dan menerima tanggung jawab, mencari informasi dan menarik kesimpulan, ketika mereka secara aktif memilih, menyusun, mengatur, menyentuh, merencanakan,menyelidiki, mempertanyakan, dan membuat kepUtusan, mereka mengaitkan isi akademis dengan konteks dalam situasi kehidupan, dan dengan cara ini mereka menemukan makna (Johnson, 2011: 35).

Muslich (2011: 50) menjelaskan bahwa salah satu strategi pembelajaran kontekstual adalah pembelajaran berbasis masalah. Berdasarkan studi dokumentasi terkait laporan akhir mahasiswa, melalui pembelajaran kontekstual mahasiswa telah mampu menunjukkan tindakan moral yang tepat yakni dengan membantu menyusun rencana pembelajaran yang disesuaikan dengan kemampuan dan kebutuhan anak berkebutuhan khusus yang mereka temui sebagai bentuk alternatif solusi dari permasalahan yang mereka temui. Hal tersebut menujukkan bahwa mahasiswa memiliki karakter bersemangat dan bertanggung jawab dalam membantu anak berkebutuhan khusus.

Hasil penelitian ini menunjukkan bahwa Mata Kuliah Anak Berkebutuhan Khusus dan Pendidikan Inklusi dapat menamankan nilai karakter dan moral mahasiswa ketika tidak berhenti pada penjelasan materi perkuliahan saja, tetapi ada pengalaman langsung dalam membantu anak berkebutuhan khusus baik yang bersekolah di SLB maupun SD Inklusif. Hasil penelitian ini sesuai dengan teori Lickona (2013: 85-100) yang mendeskripsikan masing-masing komponen dalam pembinaan karakter dan dapat diperoleh mahasiswa selama proses perkuliahan Mata Kuliah Anak Berkebutuhan Khusus dan Pendidikan Inklusi.

Komponen pertama adalah Pengetahuan Moral (Moral Knowing): Dalam komponen ini terdapat enam aspek sebagai tujuan diajarkanya moral knowing. Enam aspek tersebut meliputi kesadaran moral / moral awareness; mengetahui tentang nilai moral / knowing moral values; penentuan perspektif / perspective taking; pemikiran moral / moral reasoning; pengambilan keputusan / decision making; dan pengetahuan pribadi / self knowledge moral feeling. Komponen kedua adalah Perasaan Moral (Moral Loving); Dalam komponen ini terdapat enam aspek dari emosinal yang harus dirasakan oleh seseorang untuk menjadi manusia berkarakter yaitu: hati nurani / conscience; harga diri / self esteem; empati / empathy; mencintai hal yang baik / loving the good; kontrol diri / self control; dan kerendahan diri / huminity. Komponen ketiga adalah Tindakan Moral (Moral Action); Tindakan moral merupakan hasil (outcome) dari 2 komponen karakter lainya. Untuk memahami apa yang mendorong individu dalam perbuatan yang baik (act morally) maka harus dilihat tiga aspek lain dari karakter yaitu: kompetensi / competence; keinginan / will; dan kebiasaan / habbit.

Pengetahuan Moral (Moral Knowing) dapat ditanamkan kepada mahasiswa melalui Mata Kuliah Anak Berkebutuhan Khusus dan Pendidikan Inklusi melalui penyajian materi secara komprehensif dan mendalam tentang beragam kebutuhan khusus, kemampuan dan hambatan yang dimiliki utamanya dalam era inklusi. Perasaan Moral (Moral Feeling) dapat ditanamkan kepada mahasiswa melalui Mata Kuliah Anak Berkebutuhan Khusus dan Pendidikan Inklusi melalui interkasi secara langsung kepada anak berkebutuhan khusus baik di SLB maupun di SD inklusif. Tindakan Moral (Moral Action) mahasiswa dapat terlatih ketika mereka dibimbing menyusun laporan terkait solusi yang dapat ditawarkan khususnya dalam kegiatan pembelajaran untuk membantu anak berkebutuhan khusus yang telah mereka temui. 
Mahasiswa PGSD selaku calon guru SD sangat memerlukan penanaman nilai karakter dan moral sebelum menjadi seorang guru. Lickona dalam Erawati, dkk (2016: 4) mengungkapkan bahwa guru harus mampu mendidik dan menanamkan nilai moral. Jika guru bermaksud menanamkan nilai moral, maka yang harus dilakukan: Pertama, guru menjadi seorang penyayang yang efektif. Kedua, guru menjadi seorang model, yaitu orang-orang yang beretika yang menunjukkan rasa hormat dan tanggung jawab yang tinggi baik di dalam maupun di luar kelas. Ketiga, guru menjadi mentor yang beretika.

Zuchdi (2008: 6-8) dalam Winarni (2013) mengemukakan supaya pendidikan moral/nilai (pendidikan karakter) tidak bersifat indoktrinatif, mahasiswa perlu didorong untuk dapat menemukan alasan-alasan yang mendasari keputusan moral. Tujuanya untuk mengembangkan kemampuan mengontrol tindakan yang diperlukan agar seseorang dapat benar-benar memahami keputusan moral yang diambilnya, dapat mengidentifikasi alasan yang baik yang harus diterima dan alasan yang tidak baik yang harus ditolak atau diubah.

Berdasarkan 18 nilai karakter yang telah dirumuskan dalam Pusat Kurikulum, Balitbang Diknas yakni (1) Religius; (2) Jujur; (3) Toleransi; (4) Disiplin; (5) Kerja Keras; (6) Kreatif; (7) Mandiri; (8) Demokratis; (9) Rasa Ingin Tau; (10) Semangat Kebangsaan; (11) Cinta Tanah Air; (12) Menghargai Prestasi; (13) Bersahabat/Komunikatif; (14) Cinta Damai; (15) Gemar Membaca; (16) Peduli Lingkungan; (17) Peduli Sosial; dan (18) Tanggung Jawab, setidaknya terdapat 5 karakter yang dapat ditanamkan pada mahasiswa melalui Mata Kuliah Anak Berkebutuhan Khusus dan Pendidikan Inklusi yakni karakter toleransi, semangat kebangsaan, bersahabat / komunikatif, peduli sosial dan tanggung jawab.

Menurut Frankena (Adisusilo, 2012: 128) yang dikutip oleh Setiawan (2013) mengemukakan bahwa tujuan pendidikan moral mencakup: (1) membantu peserta didik untuk dapat mengembangkan tingkah-laku yang secara moral baik dan benar, (2) membantu peserta didik untuk dapat meningkatkan kemampuan refleksi secara otonom, (3) membantu peserta didik untuk menginternalisasikan nilai-nilai moral, norma-norma dalam menghadapi kehidupan konkretnya, (4) membantu peserta didik untuk mengadopsi prinsip-prinsip universal, nilai-nilai kehidupan sebagai pijakan untuk pertimbangan moral dalam menentukan suatu keputusan, dan (5) membantu peserta didik untuk mampu membuat keputusan yang benar, bermoral, dan bijaksana.

Moral/karakter yang dimiliki mahasiswa sebagai calon guru tersebut kelak juga dapat membantu mereka dalam membantu siswa mereka yang berkebutuhan khusus di kelas inklusi. Riasti (2015: 5) menjelaskan bahwa dalam kelas inklusi guru perlu menentukan nilai-nilai karakter yang menjadi prioritas untuk ditanamkan pada siswa. Guru menekankan pada nilai karakter toleransi dan peduli. Guru menjelaskan nilai-nilai karakter tersebut secara terintegrasi dalam pembelajaran. Guru menjelaskan dengan memberikan contoh kontekstual kepada siswa. Guru berupaya untuk menggali materi pembelajaran dalam menanamkan konsep mengenai karakter menghargai dan membantu. Guru berupaya memberikan contoh tindakan yang sesuai dan tidak sesuai dengan nilai-nilai karakter.

Karakter toleransi dapat ditanamkan dengan mahasiswa melihat secara langsung kemampuan dan hambatan yang dialami siswa berkebutuhan khusus sehingga tidak menyamaratakan kemampuan bahkan membanding-bandingkan anak berkebutuhan khusus dengan anak lain yang tidak berkebutuhan khusus. Karakter semangat kebangsaan terwujud dengan kefahaman mahasiswa bahkan anak berkebutuhan khusus juga merupakan bagian dari bangsa Indonesia yang berhak memperoleh pendidikan bersama anak lain yang tidak berkebutuhan khusus. Penanaman nilai karakter bersahabat/komunikatif pada mahasiswa dapat terwujud melalui interaksi langsung mahasiswa dengan anak berkebutuhan khusus, guru kelas, guru pendamping khusus, serta orang tua anak berkebutuhan khusus. Karakter peduli sosial dan tanggung jawab dapat ditanamkan kepada mahasiswa sebagai calon guru melalui dengan melaporkan dan menindak lanjuti hasil studi lapangan mereka melalui kegiatan menyusun program pembelajaran yang dapat membantu anak berkebutuhan khusus.

\section{Simpulan}

Mata Kuliah Anak Berkebutuhan Khusus dan Pendidikan Inklusi selain membekali mahasiswa dalam mengenal ragam kebutuhan khusus anak, juga bertujuan agar mahasiswa memiliki karakter 
terutama kepedulian dengan anak berkebutuhan khusus di lingkungan sekitarnya. Dalam mencapai tujuan tersebut, perkuliahan Mata Kuliah Anak Berkebutuhan Khusus dan Pendidikan Inklusi dapat dilaksanakan dalam berbagai setting perkuliahan. Melalui 3 setting kegiatan perkuliahan (pemaparan materi di kelas, studi lapangan, dan penyusunan laporan terkait tindak lanjut studi lapangan), terdapat 5 karakter yang dapat mahasiswa PGSD selaku calon guru SD sangat memerlukan penanaman nilai karakter dan moral sebelum ditanamkan pada mahasiswa melalui Mata Kuliah Anak Berkebutuhan Khusus dan Pendidikan Inklusi yakni karakter toleransi, semangat kebangsaan, bersahabat/komunikatif, peduli sosial dan tanggung jawab.

Berdasarkan hasil temuan dan pembahasan penelitian ini, peneliti merumuskan beberapa saran sebagai berikut: Mata Kuliah Anak Berkebutuhan Khusus dan Pendidikan Inklusi dapat diselenggarakan dengan berbagai variasi model dan setting perkuliahan dengan tetap memperhatikan ketercapaian kompetensi mata kuliah dan penanaman karakter bagi mahasiswa. Selain itu peneliti juga mengharapkan adanya kerjasama dari segenap stake holder pendidikan bagi anak berkebutuhan khusus, khususnya pihak SLB dan Sekolah Inklusif untuk membantu mahasiswa dalam melaksanakan kegiatan observasi pembelajaran di sekolah.

\section{Referensi}

Erawati, Eka Leli. dkk. 2016. Pendidikan Karakter Bangsa Pada Anak Berkebutuhan Khusus dalam Pendidikan Inklusi. Jurnal Studi Sosial, Vol 4 No 1.

Johnson, Elaine B. 2011. Contextual Teaching \& Learning, Menjadikan Kegiatan Belajar Mengajar Mengasyikkan dan Bermakna. Bandung: Kaifa Learning

Lickona, Thomas. 2013. Mendidik untuk Membentuk Karakter Bagaimana Sekolah dapat Mengajarkan Sikap Hormat, dan Tanggung Jawab. Jakarta: PT. Bumi Aksara.

Muslich, Masnur. 2011. KTSP, Pembelajaran berbasis Kompetensi dan Kontekstual. Jakarta: Bumi Aksara

Pamungkas, Bayu. 2016. Urgensi Pendidikan Karakter untuk Mengoptimalkan Layanan Pendidikan bagi Siswa Berkebutuhan Khusus di Sekolah Inklusif. Prosiding Seminar Nasional Universitas PGRI Yogyakarta, ISBN 978-602-73690-7-8

Pusat Kurikulum dan Perbukuan. 2011. Panduan Pelaksanaan Pendidikan Karakter. Jakarta: Pusat Kurikulum dan Perbukuan.

Riasti, Erlis. 2015. Implementasi Pendidikan Karakter Pada Kelas Inklusi di SD Negeri Widoro Kecamatan Pengasih Kabupaten Kulon Progo. Jurnal Pendidikan Guru Sekolah Dasar Edisi 9 Tahun ke IV Mei 2015.

Setiawan, D. 2013. Peran Pendidikan Karakter dalam Mengembangkan Kecerdasan Moral. Jurnal Pendidikan Karakter. Online, No. 1, Tahun III, Februari 2013.

Undang-Undang Republik Indonesia No. 20 tahun 2003 Tentang Sistem Pendidikan Nasional. Jakarta: Depdiknas

Winarni, S. 2013. Integrasi Pendidikan Karakter dalam Perkuliahan. Jurnal Pendidikan Karakter. (Online), 